\title{
The Roles of IgG, IgM Rheumatoid Factor, and their Complexes in the Induction of Polymorphonuclear Leukocyte Chemotactic Factor from Complement
}

\author{
Teresa Wagner, George Abraham, and John Baum \\ From the Arthritis and Clinical Immunology Unit, Monroe Community Hospital, \\ and the Department of Medicine, University of Rochester School of Medicine \\ and Dentistry, Rochester, New York 14642
}

A B S T RACT The induction of chemotactic factor by rheumatoid factor (RF) and by rheumatoid complexes and their constituents was investigated. The presence of chemotactic factor was measured by the number of polymorphonuclear leukocytes (obtained from normal individuals) attracted through a $3 \mu \mathrm{m}$ Millipore filter and is expressed as a "chemotactic index." The chemotactic index was used to measure the effect of immunoglobulins and their complexes in stimulating production of complement-derived chemotactic factors from the sera of normal individuals.

Two sources of IgG (F-II and DEAE-purified IgG) were used. These were prepared for use in the native and heat-aggregated states. The same chemotactic index was obtained with both these preparations of IgG. The chemotactic index increases when $(a)$ increasing concentrations of gamma globulin were added to a constant concentration of complement and $(b)$ when the amount of complement alone was increased.

The addition of a purified IgM RF to the mixture of IgG and complement caused a decrease in the chemotactic index. Incubation of IgG and complement before addition of IgM RF produced no change in the chemotactic index. The addition of a nonrheumatoid factor IgM to $\operatorname{IgM}$ and complement had no effect on the chemotactic index. IgM RF and IgG alone were not chemotactic.

These studies confirm the concept of "complement deviation" by IgM RF which occurs with, and as a result

This work was presented in part at the 36th Annual Meeting of the American Rheumatism Association, Dallas, Tex., 9 June 1972.

Dr. Wagner's present address is: Instytut Rheumatologiczny, Warszawa ul, Spartanska 1, Poland.

Received for publication 29 March 1973 and in revised form 21 September, 1973. of, the immune complex formation between IgG and IgM RF. The successful activation of complement chemotactic factors by IgG may explain the synovitis with high polymorphonuclear leukocyte counts found in RFnegative arthritis.

\section{INTRODUCTION}

Previous studies have demonstrated that polymorphonuclear leukocytes $(\mathrm{PMN})^{1}$ obtained from patients with rheumatoid arthritis exhibited decreased chemotaxis (1). Diminished chemotaxis has also been produced by incubation of PMN obtained from normal individuals with complexes prepared from purified rheumatoid factor and gamma-G globulin (1). However, even in those patients with decreased chemotaxis of their peripheral PMN, an acutely inflamed rheumatoid arthritic joint contains large numbers of PMN that have actively migrated into the joint. In this investigation, an attempt has been made to elucidate some factors which may be responsible for the attraction of $\mathrm{PMN}$ into the synovial fluid of the patient with rheumatoid arthritis. Since about $20 \%$ of patients with clinical rheumatoid arthritis are rheumatoid factor negative, other mechanisms (aside from complement activation by immune complex formation) can be present which may induce the chemotaxis of PMN into the joint. In these studies, results are obtained with an in vitro system which shows that even in the absence of rheumatoid factor and rheumatoid factor complexes, complement may be activated by gamma-G globulin so that chemotactic factors are produced. Further, the inhibitory effects of rheumatoid factor on the activation of chemotactic factors will be shown.

${ }^{1}$ Abbreviations used in this paper: F-II, fraction II; $\mathrm{PMN}$, polymorphonuclear leukocytes.

The Journal of Clinical Investigation Volume 53 June 1974-1503-1511 


\section{MATERIALS}

PMN were obtained primarily from a normal population of four or five laboratory personnel in whom a standard chemotactic index has been reproduced on numerous occasions. The sera used as a complement source for these studies were principally from two individuals. Serum from a third individual was occasionally used. All were serotype $\mathrm{AB}$ and $\mathrm{Rh}$ negative. Blood was obtained in $50-\mathrm{ml}$ bleedings; serum was immediately removed, stored in $2-\mathrm{ml}$ portions at $-70^{\circ} \mathrm{C}$, and utilized within $2 \mathrm{mo}$.

\section{Gamma globulin preparations}

\section{Fraction II}

Fraction II (F-II) (Difco Laboratories, Detroit, Mich.) was used in aggregated and unaggregated forms. Before use, the F-II was dissolved in Hanks' solution (Difco Laboratories) and freed of aggregates by centrifugation at $35,000 \mathrm{rpm}$ for $90 \mathrm{~min}$ in a Beckman Model L preparative ultracentrifuge (Beckman Instruments, Inc., Spinco Div., Palo Alto, Calif.). The upper two-thirds of this solution (termed "supernate") was utilized. This material was initially checked for the presence of aggregates by the centrifugation procedure with ${ }^{125}$ I-labeled F-II, and then by placing an aliquot of the supernate on a $10-40 \%$ sucrose gradient. The gradient was centrifuged at $35,000 \mathrm{rpm}$ for $15 \mathrm{~h}$ and separated into 30 fractions. Radioactivity in the bottom two fractions was considered to consist of aggregates. This comprised less than $10 \%$ of the total radioactivity in the gradient.

Aggregation procedure. A solution of F-II in Hanks' medium was heated to $63^{\circ} \mathrm{C}$ for $10 \mathrm{~min}$. The resulting flocculent was precipitated twice with $0.72 \mathrm{M}$ sodium sulfate (2). The precipitate was resuspended in Hanks' solution to the required concentration. Most aggregation was performed in a $\mathrm{pH}$ range of 6.8-7.2. In a few experiments aggregation was performed at $\mathrm{pH} 8.0$.

Immunoglobulin $G$. IgG used was DEAE purified (Miles Laboratory, Inc., Miles Research Div., Kankakee, Ill.). This was treated similarly to the F-II.

\section{Rheumatoid FACTOR}

This was prepared as previously described (3) by immunoabsorption of serum from a patient with rheumatoid arthritis by utilizing bromoacetyl cellulose-human IgG. The strongly latex-positive material obtained was subjected to Sephadex G-200 chromatography and shown to consist of only IgM by immunodiffusion, and of a single component by isoelectric focusing and analytical ultracentrifugation.

\section{Normal IGM}

Normal IgM was prepared by chromatography of normal human serum on Sephadex G-200 (Pharmacia Fine Chemicals, Inc., Piscataway, N. J.). The first peak eluted was then further purified by DEAE column chromatography by utilizing a linear $0.015-0.15 \mathrm{M}, \mathrm{pH} 7.35$, phosphate buffer gradient. A latex agglutination test for anti-IgG activity of the $\operatorname{IgM}$ obtained was negative. The material utilized contained no $\operatorname{IgG}$ or $\operatorname{Ig} \mathrm{A}$ by immunodiffusion.

\section{Complement sources}

The AB Rh-negative sera used as the source of complement were utilized at dilutions of $1,10,20$, and $33 \frac{1}{3} \%$ in Hanks' solution. In these sera, IgG was present at con- centrations of 940 and $1240 \mathrm{mg} / 100 \mathrm{ml}$ of serum, respectively. The "concentration of complement" in this study refers to the serum dilution.

\section{METHODS}

In each set of experiments, two to four chambers were used for each test situation and each control. Controls consisted of chambers with either sera (without added immunoalone.

globulin or complexes) or immunoglobulin preparations

The method for inducing chemotaxis of PMN, previously described in detail $(1,4)$, is based on the method of Boyden (5) and is similar to the procedure described by Ward, Cochrane, and Muller-Eberhard (6).

Blood is obtained from normal individuals in $10-\mathrm{ml} \mathrm{Vacu-}$ tainer tubes (Becton-Dickinson and Co., Rutherford, N. J.) containing heparin. To this is added $0.75 \mathrm{ml}$ of a $2 \%$ solution of methyl cellulose in normal saline (7). After standing at room temperature for $30-45 \mathrm{~min}$, the plasma layer is removed. The now enriched concentration of PMN is spun down in a Shandon Cytocentrifuge (Shandon Southern Instruments Inc., Sewickley, Pa.) and directly deposited on a 3- $\mu \mathrm{m}$ Millipore filter (Millipore Corp., Bedford, Mass.). The filter is immediately removed and placed into a modified Sykes-Moore tissue culture chamber (Bellco Glass, Inc., Vineland, N. J.). Through ports in the chamber, solutions may be injected into the upper (starting side for cell migration) or lower compartments, which are separated by the filter. Hanks' solution is usually placed in the upper compartment with the PMN. In one or two experiments which will be noted, serum (as a source of complement) was placed in the upper compartment as a control. The bottom compartment was filled with the test solutions which will be described. After filling, the chamber was incubated for $3 \mathrm{~h}$ at $37^{\circ} \mathrm{C}$. After incubation, the filters were removed and stained by Boyden's method (5), trimmed, and mounted on microscope slides. The cells on both sides of the Millipore filter were counted by the use of a $1-\mathrm{cm}$ square ocular grid divided into $2 \times 2-\mathrm{mm}$ boxes (8).

The chemotactic index is the number of cells counted in five of the $2-\mathrm{mm}$ squares on the attractant side of the filter, divided by the number of cells on the starting side in a single 2- $\mathrm{mm}$ square. The dividend obtained is multiplied by 500 to produce the chemotactic index. The fields counted were selected to avoid any areas which showed clumping of cells. 10 fields are counted on each filter.

F-II was initially used at concentrations ranging from $0.01 \mu \mathrm{g} / \mathrm{ml}$ to $10 \mathrm{mg} / \mathrm{ml}$. Subsequent experiments were performed at concentrations of F-II and IgG from 0.001 to $0.1 \mathrm{mg} / \mathrm{ml}$.

Control experiments were performed with inactivated sera $\left(56^{\circ} \mathrm{C}\right.$ for $\left.30 \mathrm{~min}\right)$ to which the aggregated or unaggregated F-II had been added.

Experiments were performed which compared the chemotaxis induced by aggregated and unaggregated F-II to that obtained with DEAE column-purified aggregated or unaggregated IgG.

Experiments were performed with prior heating of the aggregated F-II to $65^{\circ} \mathrm{C}$ for $20 \mathrm{~min}$. The F-II was subsequently precipitated by the sodium sulfate method (2). This was to destroy any possible enzyme activity which might have been responsible for activation of chemotactic factors from complement. In similar experiments with unaggregated $\mathrm{F}$-II, the material was heated at $56^{\circ} \mathrm{C}$ for $30 \mathrm{~min}$. The supernate of the centrifuged solution was used. 
To rule out serum factors on the surface of the PMN, several experiments were performed with the PMN washed three times in Hanks' solution before centrifugation onto the Millipore filter.

F-II and IgG were combined in some experiments with IgM rheumatoid factor and IgM free of rheumatoid factor activity. In all of these experiments, equal concentrations of IgG and IgM were used. The concentration ranges were $0.01-0.1 \mathrm{mg} / \mathrm{ml}$.

In order to investigate the deviation or inactivation of chemotactic factor, several experiments were performed with prior incubation of the serum (complement), gamma globulin and IgM rheumatoid factor in the following combinations: (a) F-II plus complement was incubated at $37^{\circ} \mathrm{C}$ for $30 \mathrm{~min}$. Then rheumatoid factor was added and the mixture placed in the lower compartment of the migration chamber for the 3-h incubation period; and (b) rheumatoid factor plus complement was incubated at $37^{\circ} \mathrm{C}$. for 30 min. Then F-II was added and the mixture placed in the lower compartment for the 3-h incubation period.

\section{RESULTS}

Initially the effects of aggregated and nonaggregated gamma-G-globulin (F-II) were compared at varying concentrations. The results are seen in Table I. The concentration of the complement was held at $33 \frac{1}{3} \%$. Comparisons of the chemotactic values obtained by using concentrations of F-II from 10 to $0.00001 \mathrm{mg} / \mathrm{ml} \mathrm{dem-}$ onstrate no significant differences when unaggregated or aggregated material was placed in the lower chamber with complement. Studies performed with $33 \frac{1}{3} \%$ complement alone yielded a chemotactic index of $363.1 \pm 47.1$. Since, as noted above, the IgG content of the serum used as a complement source was approximately $10 \mathrm{mg} / \mathrm{ml}$, a concentration of added F-II of $1 \mathrm{mg} / \mathrm{ml}$ thus only raises the total concentration of IgG in the chamber about $20 \%$. The relationship of the chemotactic index to the concentration of gamma globulin is apparent when it is seen that chemotactic indices significantly greater than the values for serum alone are not reached until this

TABLE I Chemotaxis of PMN with Aggregated and Unaggregated F-II

\begin{tabular}{|c|c|c|c|c|}
\hline \multirow[b]{3}{*}{$\begin{array}{l}\text { Concentration } \\
\text { of F-II }\end{array}$} & \multicolumn{4}{|c|}{ Chemotactic index (mean \pm SEM) } \\
\hline & \multicolumn{2}{|c|}{ Aggregated } & \multicolumn{2}{|c|}{ Unaggregated } \\
\hline & $\begin{array}{c}\text { With } \\
\text { comple- } \\
\text { ment* }\end{array}$ & $\begin{array}{l}\text { Without } \\
\text { comple- } \\
\text { ment }\end{array}$ & $\begin{array}{c}\text { With } \\
\text { comple- } \\
\text { ment* }\end{array}$ & $\begin{array}{l}\text { Without } \\
\text { comple- } \\
\text { ment }\end{array}$ \\
\hline \multicolumn{5}{|l|}{$m g / m l$} \\
\hline 10.0 & $640.7 \pm 158.3$ & - & $779.5 \pm 172.7$ & - \\
\hline 1.0 & $620.9 \pm 64.9$ & - & $620.0 \pm 64.9$ & - \\
\hline 0.2 & $336.9 \pm 61.2$ & - & $477.0 \pm 42.5$ & - \\
\hline 0.1 & $336.2 \pm 49.0$ & 46.8 & $424.0 \pm 36.4$ & 60.0 \\
\hline 0.01 & $419.9 \pm 65.3$ & 46.0 & $389.3 \pm 36.4$ & 44.4 \\
\hline 0.001 & $338.2 \pm 59.5$ & 62.8 & $356.3 \pm 49.5$ & 64.9 \\
\hline 0.0001 & $254.4 \pm 77.2$ & 38.6 & $228.6 \pm 43.8$ & 62.5 \\
\hline 0.00001 & $55.0 \pm 10.8$ & - & $112.5 \pm 28.6$ & - \\
\hline
\end{tabular}

* Complement-331\%.
TABLE II

Chemotaxis of $P M N$ 's with Different Concentrations of Complement and Aggregated F-II

\begin{tabular}{ccc}
\hline $\begin{array}{c}\text { Complement } \\
\text { concentration }\end{array}$ & $\begin{array}{c}\text { Aggregated } \\
\text { F-II }\end{array}$ & $\begin{array}{c}\text { Chemotactic index } \\
\text { (mean } \pm \text { SEM) }\end{array}$ \\
\hline$\%$ & $m g / m l$ & \\
$33 \frac{1}{3}$ & 0 & $363.1 \pm 97.1$ \\
20 & 0 & $262.5 \pm 24.3$ \\
10 & 0 & $233.5 \pm 51.5$ \\
1 & 0 & $48.3 \pm 11.7$ \\
$33 \frac{1}{3}$ & 0.01 & $419.9 \pm 65.3$ \\
20 & 0.01 & $394.0 \pm 127.6$ \\
10 & 0.01 & $223.8 \pm 56.5$ \\
1 & 0.01 & $132.4 \pm 17.5$ \\
\hline
\end{tabular}

concentration of added F-II (aggregated or unaggregated) was reached.

Further evidence that the chemotactic factors are produced by activation of complement by the added F-II was provided. In 15 control experiments, F-II at a concentration of $0.01 \mathrm{mg} / \mathrm{ml}$ was added to inactivated sera $\left(56^{\circ} \mathrm{C}\right.$ for $\left.30 \mathrm{~min}\right)$. The mean chemotaxis was reduced to 86.6 \pm 13.4 . Several experiments were performed to rule out the possibility that activity of the unaggregated gammaglobulin was due to the presence of small amounts of aggregated material present in the preparations. The F-II utilized was thus labeled with ${ }^{125} \mathrm{I}$. After labeling, it was centrifuged at $35,000 \mathrm{rpm}$ and the top two-thirds of the centrifuged preparation removed. A portion was then placed on a sucrose gradient and centrifuged at $35,000 \mathrm{rpm}$ at $4^{\circ} \mathrm{C}$ for $15 \mathrm{~h}$. The gradient was collected in 30 fractions and each was counted in a gamma counter.

The percentage of radioactivity found in the bottom of the gradient averaged $9.8 \%$ of the total amount of radioactivity. Thus, $90 \%$ of the gamma $\mathrm{G}$ globulin in these experiments was present as unaggregated material. Since numerous concentrations of F-II were utilized, this amount of aggregation does not appear to influence the data, since no significant difference in activity is noted between the two forms of the gamma G globulin (Table I).

In order to measure the effect of the serum used as the source of complement, experiments were performed using $33 \frac{1}{3}, 20,10$, and $1 \%$ concentrations of serum diluted in Hanks' solution. The results are noted in Table II. Although an overall decrease is noted as the serum concentration is lowered, the most marked drop is seen between $33 \frac{1}{3}$ and $20 \%$ and from 10 to $1 \%$. Most of the studies reported in this paper were performed at serum concentrations of $33 \frac{1}{3}$ and $20 \%$ and are noted for the appropriate experiments.

To rule out the possibility that the mode of preparation of the gamma $G$ globulin might in some way be re- 
TABLE III

Chemotaxis of PMN at Different Complement Concentrations with Different Preparations of Aggregated and Unaggregated $F$-II and IgG

\begin{tabular}{|c|c|c|c|}
\hline \multirow{3}{*}{$\begin{array}{l}\text { Comple- } \\
\text { ment } \\
\text { concen- } \\
\text { tration }\end{array}$} & \multirow{3}{*}{$\begin{array}{c}\text { IgG } \\
\text { concentration }\end{array}$} & \multicolumn{2}{|c|}{$\begin{array}{l}\text { Chemotactic index } \\
(\operatorname{mean} \pm \mathrm{SEM})\end{array}$} \\
\hline & & \multicolumn{2}{|c|}{ Aggregated } \\
\hline & & IgG* & F-II \\
\hline$\%$ & $m g / m l$ & & \\
\hline \multirow[t]{3}{*}{$33 \frac{1}{3}$} & 0.1 & $289.0 \pm 60.5$ & $336.0 \pm 42.0$ \\
\hline & 0.01 & $295.9 \pm 44.8$ & $419.9 \pm 65.3$ \\
\hline & 0.001 & $462.2 \pm 146.0$ & $338.2 \pm 59.9$ \\
\hline \multirow[t]{5}{*}{20} & 0.1 & $368.0 \pm 52.0$ & $305.4 \pm 40.4$ \\
\hline & 0.01 & $270.5 \pm 88.0$ & $384.0 \pm 127.6$ \\
\hline & 0.001 & $253.3 \pm 47.0$ & $497.2 \pm 244.3$ \\
\hline & & \multicolumn{2}{|c|}{ Unaggregated } \\
\hline & & IgG & F-II \\
\hline \multirow[t]{3}{*}{$33 \frac{1}{3}$} & 0.1 & $434.6 \pm 69.9$ & $424.0 \pm 42.5$ \\
\hline & 0.01 & $459.6 \pm 95.3$ & $389.3 \pm 36.4$ \\
\hline & 0.001 & $444.4 \pm 59.5$ & $356.3 \pm 49.5$ \\
\hline \multirow[t]{3}{*}{20} & 0.1 & $658.0 \pm 194.4$ & $271.0 \pm 36.7 \S$ \\
\hline & 0.01 & $462.5 \pm 99.4$ & $268.0 \pm 53.6$ \\
\hline & 0.001 & $525.8 \pm 119.9$ & $301.1 \pm 61.5$ \\
\hline
\end{tabular}

* IgG-Miles Laboratories.

$\ddagger$ F-II-Difco Laboratories.

$\S P=0.02$-all other $P$ not significant.

lated to the chemotactic results obtained, comparisons were made between unaggregated and aggregated DEAE-purified IgG and the F-II (Difco Laboratories). Although the F-II utilized here is almost entirely IgG, we could not rule out the effect of contamination by other constituents or of preparative denaturation of the protein. The results of these experiments are seen in Table III.

In these experiments, $\operatorname{IgG}$ concentrations from 0.1 to $0.001 \mathrm{mg} / \mathrm{ml}$ in $33 \frac{1}{3}$ and $20 \%$ serum were used. Essentially no difference between the two preparations was noted when the data were analyzed by statistical means. One group of studies ( $20 \%$ complement, $0.1 \mathrm{mg} / \mathrm{ml}$ of unaggregated F-II and IgG) were significantly different at the 0.02 level. This difference between the two preparations is noted in Table III. It stands as an isolated finding, and we do not feel that this represents a true difference between the two preparations. Control experiments were performed with the IgG alone to rule out the possibility of chemotactic activity from contamination by kallekrein in this preparation. ${ }^{2}$ At concentrations of $0.1-0.001 \mathrm{mg} / \mathrm{ml}$ of $\mathrm{IgG}$, the chemotactic ac-

${ }^{2}$ J. D. Smiley. Personal communication. tivity was $18 \pm 3.7$ with aggregated IgG and $24 \pm 4.3$ with unaggregated IgG.

In several experiments, the possibility was tested that the similar effects on the induction of chemotactic factors by both aggregated and unaggregated F-II was due to the method of aggregation. A comparison was thus made of the chemotactic index induced by the addition of aggregated F-II prepared in three different ways from a single batch of F-II. To destroy enzymes which might activate the production of chemotactic factors, the aggregated material was first prepared by heating the F-II in Hanks' solution to $65^{\circ} \mathrm{C}$ for $20 \mathrm{~min}$. The chemotactic index was $595 \pm 80$. To check $\mathrm{pH}$ effects, some of this aggregated F-II was precipitated twice with

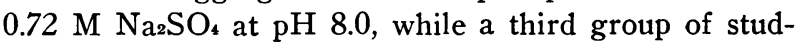
ies was performed with the sodium sulfate precipitation at $\mathrm{pH}$ of 6.8 . In the former, the chemotactic index was $431 \pm 89$ and in the latter experiment, $467 \pm 98$. This was done to test the effects of a mildly alkaline $\mathrm{pH}$ on the cells or on the aggregated F-II. The results demonstrate that there was no significant effect with any of the three methods of preparation of F-II.

The status of the PMN used in these experiments was next investigated. With the technique utilized here, the cells, after concentration with methylcellulose, are placed directly into the cell centrifuge and spun onto the Millipore filter. Excess plasma is removed by a filter paper pad. In this group of experiments, the cells were washed three times with Hanks' solution before placing them in the centrifuge. No differences were noted between unwashed and washed cells. This mitigates against the effects of any cell-bound globulin or complement components from the cell donor affecting the results.

A series of experiments was then performed to look at the activation of chemotactic factors by using the complex formed from rheumatoid factor and IgG. Various experiments were performed which involved prior

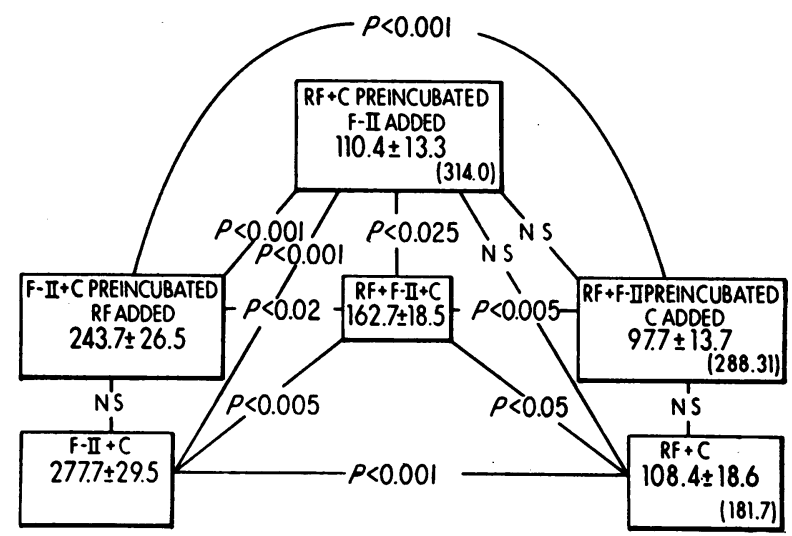

FIGURE 1 Interrelationships of IgG, IgM rheumatoid factor (RF), and normal $\operatorname{IgM}$ in the induction of chemotactic factors from complement (C). 
incubation of one or both immunoglobulin components with complement and each other. A number of experiments were also performed to compare a nonrheumatoid factor IgM with the IgM rheumatoid factor. In Fig. 1 the data are displayed so that the relationship of the results to the different test conditions can be readily observed. In the left-hand corner is noted the expected result of the reaction of complement with a concentration of F-II at $0.01 \mathrm{mg} / \mathrm{ml}$. When rheumatoid factor is added to the other components, there is a significant drop in the chemotactic index to 162.7. This value (shown in the center) demonstrates the inhibitory effect of rheumatoid factor on the activation of chemotactic factor. If, however, the F-II and complement are preincubated and the rheumatoid factor then added (center left), a chemotactic index of 243.7 is obtained. This value is significantly higher than that reached when the rheumatoid factor was initially present with the F-II and complement. Since activation of complement takes place before addition of the rheumatoid factor, the value obtained is in the same range as that for the F-II and complement alone.

The deviation of complement (reduction of complement activation) by the rheumatoid factor is also seen in two further experiments. At the top center of the figure, results are shown in which rheumatoid factor and complement are preincubated and then F-II is added. A chemotactic index of 110.4 is obtained. This demonstrates that the rheumatoid factor inhibited the production of chemotactic factor with deviation of complement activation, since addition of the F-II did not induce chemotaxis. This idea is further substantiated by comparison of the index in this experiment with that shown in the lower right where a similar chemotactic index was obtained with rheumatoid factor and complement alone, i.e., without addition of F-II. This same degree of inhibition of complement activation is also shown in the experiment in the upper right. Here, the ability of the F-II to induce complement activation was blocked by its prior incubation with rheumatoid factor.

The chemotactic indices shown in parentheses in the top and right boxes are those values produced when nonrheumatoid factor $\operatorname{IgM}$ was used instead of the rheumatoid factor. While only small amounts of material were available for a few experiments in each case, it is nevertheless apparent that deviation of complement did not occur with this material. It further shows that the effect of the rheumatoid factor appears to be specific in each case where it reacted with either complement or F-II.

In several experiments, the purified rheumatoid factor was added to the IgG prepared by column chromatography. This was done to demonstrate that a preparation of IgG of greater purity would give results similar to those seen when utilizing F-II. The same degree of complement deviation was seen with both preparations. The chemotactic index of rheumatoid factor plus F-II and complement was 162.7 , while with the purified IgG with rheumatoid factor and complement, the chemotactic index was 155.9. This demonstrates the same degree of reactivity of the rheumatoid factor with both preparations of IgG.

\section{DISCUSSION}

The preeminent hypothesis for the cause of the synovitis of rheumatoid arthritis considers the inflammatory stimulus to be the complex formed by rheumatoid factor (IgG and/or IgM) and gamma globulin (IgG) (9). The formation of this complex presumably triggers complement activation, which results in the production of chemotactic factors ( $33 a, C 5 a, C \overline{567}$ ). These attract PMN into the joint, where they phagocytose the complexes (10). The lysosomal enzymes released (11) eventually lead to destruction of the joint. However, this theory does not account for those patients in whom rheumatoid factor is not present and in whom synovitis and inflammation can be as severe as that found in rheumatoid factor-positive patients (12).

Hedberg, in a comparison of synovial fluids from factor-negative and factor-positive patients, showed no difference in the total white blood cell count of the synovial fluid (13). This was also noted previously by Hollingsworth, Siegel, and Cressey (14), who found the percentage of PMN to be as high in the synovial fluid of factor-negative patients as in those patients in whom rheumatoid factor is present. In addition, it has been shown that the IgG concentration in synovial fluids from these two groups is similar and indeed higher than in any other form of arthritis $(13,15)$. Smiley, Sachs, and Ziff (16) found the major immunoglobulin produced by explants from synovial tissue was IgG. Therefore, another mechanism, possibly related to the presence of IgG, might account for the synovitis and large numbers of PMN found in the synovial fluid of patients with factor-negative rheumatoid arthritis.

Further confirmation of the similarities in the synovial fluids from factor-positive and factor-negative patients is found in the study by Zvaifler (17) of the breakdown product of $\mathrm{C} 3$ in these two groups. To account for the presence of this product, the reaction of aggregated gamma globulin with rheumatoid factor is postulated. However, in his studies there was an equally significant number of rheumatoid factor-negative patients in whose synovial fluids this material was found. These data are consistent with the experimental results found in our studies.

The importance of IgG in rheumatoid arthritis is pointed out in another way by Larsson and Lithner 
(18), who looked at fluorescent staining in the skin and vessels of patients with rheumatoid arthritis, comparing them to controls. They found a significant difference in the localization of $\operatorname{IgG}$ and $\operatorname{IgA}$ in the walls of small cutaneous vessels. These workers point out that earlier studies also showed IgG localized in the small vessel walls in rheumatoid arthritis in synovial tissue and skin. It should be noted that they found no difference in the deposition of $\operatorname{IgM}$ between the rheumatoid arthritis and control subjects.

Restifo, Lussier, Rawson, Rockey, and Hollander (19) have suggested that inflammation may be produced by the injections of $7 \mathrm{~S}$ gamma globulin into an inactive joint of patients with rheumatoid arthritis. Although complex formation was felt to be responsible for the production of the synovitis, several interesting points are noted in their study. The highest white blood cell count reported was found in a joint injected with unaggregated gamma globulin where the synovial fluid had the lowest latex titer $(1: 40)$ of any in the study.

Subsequent investigations by Hollander, Fudenberg, Rawson, Abelson, and Torralba (20) confirmed the marked effect of unaggregated gamma globulin from rheumatoid arthritis patients on the induction of an inflammatory reaction in the joints of rheumatoid factorpositive patients. In one experiment in which nonrheumatoid gamma globulin was used, the effect of the unaggregated gamma globulin was slightly better in inducing the cellular response. These in vivo studies support the biological activity of unaggregated gamma globulin we have found in our in vitro experiments. It should be noted that Sliwinski and Zvaifler (21) in similar experiments were unable to reproduce joint inflammation with the injection of aggregated gamma globulin, although one patient responded to the injection of unaggregated gamma globulin with a marked inflammatory response (which was not reproducible).

Aggregate-free IgG has been shown to fix complement. Runge and Mills (22) showed that aggregate-free gamma globulin fixed complement in 5 of 11 patients, and the fixation found in several was up to $30 \%$. No difference was found between native or aggregated autologous IgG when they performed skin tests in rheumatoid arthritis patients. Augener, Grey, Cooper, and Muller-Eberhard at La Jolla have also demonstrated the binding of monomeric IgG with $\mathrm{C} 1$. This binding was less than that which took place after aggregation of the same native subgroup of IgG (23).

Normansell (24) found no convincing evidence that rheumatoid factor reacts more strongly with altered gamma $G$ globulin than with native gamma $G$ globulin. It is clear that the results we have obtained, which show no difference between heat-aggregated gamma G globulin and unaltered gamma $G$ globulin, are akin to a sub- sequent demonstration by Normansell (25) that the binding of rheumatoid factor to heat-aggregated gamma G globulin was not significantly stronger than that to unaltered gamma G globulin. Schur and Kunkel (26) also found that rheumatoid factor would react with unaggregated gamma globulin. Our results are consistent with the data in these studies (Fig. 1).

In the work of Hurd, LoSpalluto, and Ziff (27), it was felt by the authors that the inclusions found in normal PMN after the addition of IgM rheumatoid factor to rheumatoid factor-negative synovial fluids was due to the reaction of the added rheumatoid factor with altered gamma globulin present in the synovial fluid. However, they could not otherwise demonstrate the presence of aggregated gamma globulin. Since as indicated above, Normansell (25) and Schur and Kunkel (26) showed rheumatoid factor could react with unaggregated gamma globulin, there may not have to be a requirement for aggregation of the gamma globulin in the synovial fluid to produce the complexes.

Numerous workers have found this same phenomenon in varying degrees. Allen and Kunkel (28) called attention to an autospecific rheumatoid factor which had strong affinity for native gamma globulin. They also reported this in gamma myeloma proteins. Oreskes and Shore (29) showed that there was an inhibitory effect of added native gamma globulin on agglutination titers. Although the effect was not as marked as with the same gamma globulin aggregated by heating, there was a significant effect with the native gamma globulin. Hannestad showed in a number of experiments, that native gamma globulin was firmly bound to rheumatoid factor and demonstrated clearly that this was not aggregated gamma globulin (30). He felt that when this reactive complex was present in sera, it represented the hidden rheumatoid factors described by Allen and Kunkel (28). The complex could be inhibited by low concentrations of native gamma globulin. In these studies he was able to show that 7S gamma globulin combined firmly with isolated gamma $\mathrm{M}$ rheumatoid factor. This complex was accompanied by similar sedimentation properties and the same inhibition of rheumatoid factor activity as was noted in whole sera. Labeled 7S gamma globulin was shown in sucrose density studies to be found with the macroglobulin rheumatoid factor.

The similarity of effects with both the unaggregated and aggregated gamma globulins and their reactions with the rheumatoid factor used in this experiment has also been demonstrated by Pike and Schultz (31). They studied the inhibitory effect of several types of gamma globulin on the titer or rheumatoid arthritis sera in the sensitized sheep cell test. They found in one rheumatoid arthritis sera the same 16-fold decrease in titer with unheated human gamma globulin as with human gamma 
globulin that had been heated at $63^{\circ} \mathrm{C}$ for $10 \mathrm{~min}$. The results seen in our experiment are consistent with their findings and would indicate that the similarity of results with aggregated and unaggregated gamma globulin may be more likely due to the particular rheumatoid factor used in the studies. This was also shown by Allen and Kunkel (28) and indicates our rheumatoid factor probably represents a factor with a high specificity for native unaltered gamma $\mathrm{G}$ globulin.

In our in vitro experiments we have shown evidence that leads to a hypothesis for the role of IgG as the principle factor responsible for the chemotaxis of PMN into the joint of the rheumatoid factor-negative, as well as the rheumatoid factor-positive, patients. Indeed it appears that rheumatoid factor, by preventing the activation of chemotactic factors, may be playing a protective role. This blocking effect of rheumatoid factor on complement activation has been pointed out by several groups (32-34). Schmid, Roitt, and Rocha (32) related this effect to the concentration of $\mathrm{IgG}$ in the reaction system. Our control experiments with nonrheumatoid factor IgM show this inhibition to be a property of the rheumatoid factor activity of the macroglobulin. This "deviation" of complement by rheumatoid factor was avoided by prior incubation of $\mathrm{IgG}$ with complement (Fig. 1).

Evidence for the blocking activity of IgM antibody in complement fixation has been shown for other $\operatorname{Ig} \mathrm{M}$ antibodies beside rheumatoid factor. Scott and Russell (35) recently demonstrated a similar type of blocking of complement fixation with antidengue IgM antibody. The blocking effect of rheumatoid factor has also been found in a system where thrombocyte isoantibodies were blocked by the addition of rheumatoid factor (36).

In early rheumatoid arthritis there is apparently little relationship between the presence of large numbers of PMN and rheumatoid factor in synovial fluid. In fact, in a study by Schumacher and Kitridou (37), the patient with the highest titer of rheumatoid factor in the synovial fluid had one of the lower leukocyte counts, with a low percentage of PMN. In the two patients with the highest leukocyte count $(15,000$ and 20,000$)$, one had no rheumatoid factor and the other had a minimal amount. Both of these patients also had the highest percentage of PMN. This is of interest in the view of our finding that in the presence of rheumatoid factor, we found a decrease in chemotaxis (Fig. 1).

Since we found that adding IgG (increasing the concentration in the chamber by $20 \%$ or more) produced an increase in chemotaxis, it is apparent that the number of PMN in the joints of patients with rheumatoid arthritis may have some relationship to the high levels of gamma globulin found in the synovial fluid of patients with this disease, whether rheumatoid factor is present or absent.

Further support for the importance of gamma globulin in joint inflammation comes from the study of Chamberlain, Shapland, and Roitt (38), who showed that autologous heat-aggregated $\operatorname{IgG}$, injected intradermally in patients with rheumatoid arthritis and in controls, produces an "Arthus-type" reaction in the patients. However, their studies differ from our results because the skin reaction they produced with heat-aggregated material was significantly greater than with unaggregated IgG.

The chemotactic activity in serum alone (which serves as the source of complement) is probably due to the presence of IgG reaction with the complement. Albumin has been' shown not to be chemotactic (39). Kinsella, Baum, and Ziff (40) found morphological evidence for the association of IgG and complement factors in their appearance in a diffuse cytoplasmic staining pattern in the $\mathrm{A}$ and $\mathrm{C}$ cells of synovial tissue. The same degree of fluorescent staining was seen in rheumatoid factor-positive and rheumatoid factor-negative patients. Even in cells from rheumatoid factor-positive synovial tissue, this association was found without staining for IgG and IgM rheumatoid factors. This was confirmed by the studies of Bonomo, Tursi, Trizio, Gillardi, and Dammacco, (41) who found similar staining patterns for IgG and complement in synovial cells.

In a recent article on the pathogenesis of joint inflammation in rheumatoid arthritis, Zvaifler (42) postulated the activation of chemotactic factors by immune complexes to account for the "remarkable accumulation of neutrophiles in rheumatoid synovial effusions. ..." On the basis of our investigation, we believe the induction of chemotactic factors from complement can occur in the joint in the absence of complex formation. We feel that the clinical status of the joint inflammation in rheumatoid factor-negative patients with accumulations of PMN like that seen in factor-positive patients is more related to the similarly elevated levels of $\operatorname{IgG}$ found in their synovial fluids. However, the presence of complexes and their ingestion by the PMN and phagocytic synovial cells causes an outpouring of lysosomal enzymes into the synovial fluid. This, then, can explain the wellknown difference in the pathophysiology between these two groups of patients-the factor-positive complexforming group of patients show more erosive disease (43). Even if the IgG is altered or aggregated in the rheumatoid factor-negative patients, it apparently will have little or no effect on the release of lysosomal enzymes from PMN.

From these data, it seems probable that gamma globulin alone may be more important than complexes for the 
percent of large numbers of leukocytes in the synovial fluid. It has been well demonstrated that factor-negative rheumatoid arthritis does not lead to the degree of joint destruction seen with factor-positive arthritis. It has also been shown that lysosomal enzyme titers are lower in the synovial fluid in factor-negative arthritis (44). This would indicate that joint damage is more likely to appear when complexes can be ingested and cause leakage of lysosomal enzymes into the synovial fluid. The mere presence of the PMN in high concentrations thus is not sufficient to lead to high lysosomal enzyme levels and joint destruction. On the basis of our studies, it is apparent that rheumatoid factor complex formation is not necessary for the influx of PMN into the joint, but may theoretically inhibit this process to some extent.

\section{ACKNOWLEDGMENTS}

We are indebted to Dr. Peter Ward for his advice during the course of this study. We wish to thank Mrs. Charene Winney for expert technical assistance and Mrs. Maureen E. Laffin for her skillful preparation of this manuscript.

This study was supported in part by a grant from the Monroe County Chapter of the Arthritis Foundation.

\section{REFERENCES}

1. Mowat, A. G., and J. Baum. 1971. Chemotaxis of polymorphonuclear leukocytes from patients with rheumatoid arthritis. J. Clin. Invest. 50: 2541.

2. Christian, C. L. 1958. Characterization of the "reactant" (gamma globulin factor) in the F II precipitin reaction and the F II tanned sheep cell agglutination test. J. Exp. Med. 108: 139.

3. Abraham, G. N., R. A. Clark, and J. H. Vaughan. 1972. Characterization of an IgA rheumatoid factor: binding properties and reactivity with the subclasses of human $\gamma \mathrm{G}$ globulin. Immunochemistry. 9: 301.

4. Baum, J., A. G. Mowat, and J. A. Kirk. 1971. A simplified method for the measurement of chemotaxis of polymorphonuclear leukocytes from human blood. $J$. Lab. Clin. Med. 77 : 501.

5. Boyden, S. 1962. The chemotactic effect of mixtures of antibody and antigen on polymorphonuclear leukocytes. J. Exp. Med. 115: 453.

6. Ward, P. A., C. G. Cochrane, and H. J. Muller-Eberhard. 1966. Further studies on the chemotactic factor of complement and its formation in vivo. Immunology. 11: 141 .

7. Boyum, A. 1968. Separation of leukocytes from blood and bone marrow. A two-phase system for removal of red cells with methylcellulose as erythrocyte-aggregating agent. Scand. J. Clin. Lab. Invest. Suppl. 21: 97.

8. Zivkovic, M., and J. Baum. 1972. Chemotaxis of polymorphonuclear leukocytes from patients with systemic lupus erythematosus and Felty's syndrome. Immuno!. Commun. 1: 39.

9. Zvaifler, N. J. 1970. Further speculation of the pathogenesis of joint inflammation in rheumatoid arthritis. Arthritis Rheum. 13: 895.

10. Hurd, E. R., T. D. Kinsella, and M. Ziff. 1971. Immunohistologic studies of synoviocytes and synovial exudate cells. J. Exp. Med. 134 (Pt. 2) : $296 \mathrm{~s}$.

11. Hawkins, D., and S. Peeters. 1971. The response of polymorphonuclear leukocytes to immune complexes in vitro. Lab. Invest. 24 : 483.

12. Nesterov, A. J., and A. G. Astapenko. 1967. Aspects clinico-immunologiques de l'arthrite rheumatoide seronegative. European Congress for Rheumatology. Lisbon. October 1967.

13. Hedberg, H. 1967. Studies on synovial fluid in arthritis. Acta. Med. Scand. Suppl. 479: 36.

14. Hollingsworth, J. W., E. R. Siegel, and W. A. Cressey. 1967. Granulocyte survival in synovial exudate of patients with rheumatoid arthritis and other inflammatory joint diseases. Yale J. Biol. Med. 39: 289.

15. Hrnčír, Z., M. Tichy, M. Salavec, and J. Vazřina. 1972. Immunoglobulins $A, G$, and $M$ in synovial fluid in rheumatoid arthritis. Reactive synovitis of local origin and in post mortem synovial fluid. Ann. Rheum. Dis. 31: 325.

16. Smiley, J. D., C. Sachs, and M. Ziff. 1968. In vitro synthesis of immunoglobulin by rheumatoid synovial membrane. J. Clin. Invest. 47: 624.

17. Zvaifler, N. J. 1969. Breakdown products of $C^{\prime} 3$ in human synovial fluids. J. Clin. Invest. 48: 1532.

18. Larsson, O., and F. Lithner. 1972. Localization of various plasma proteins in the skin in rheumatoid arthritis. Acta. Med. Scand. 192: 13.

19. Restifo, R., A. J. Lussier, A. J. Rawson, J. H. Rockey, and J. L. Hollander. 1965. Studies on the pathogenesis of rheumatoid joint inflammation. III. The experimental production of arthritis by the intra-articular injection of purified 7S gammaglobulin. Ann. Int. Med. 62: 285 .

20. Hollander, J. C., H. H. Fudenberg, A. J. Rawson, N. M. Abelson, and T. P. Torralba. 1966. Further studies on the pathogenesis of rheumatoid joint inflammation. Arthritis Rheum. 9: 675 .

21. Sliwinski, A. J., and N. J. Zvaifler. 1969. The removal of aggregated and nonaggregated autologous gamma globulin from rheumatoid joints. Arthritis Rheum. 12: 504.

22. Runge, L. A., and J. A. Mills. 1971. In vivo and in vitro responses to autologous IgG in patients with rheumatoid arthritis. Arthritis Rheum. 14:631.

23. Augener, W., H. M. Grey, N. R. Cooper, and H. J. Muller-Eberhard. 1971. The reaction of monomeric and aggregated immunoglobulins with $\mathrm{Cl}$. Immunochemistry. 8: 1011.

24. Normansell, D. E. 1970. Anti- $\gamma$-globulins in rheumatoid arthritis sera-I. Studies on the $22 \mathrm{~S}$ complex. Immunochemistry. $7: 787$.

25. Normansell, D. E. 1971. Anti- $\gamma$-globulin in rheumatoid arthritis sera-II. The reactivity of anti-rglobulin rheumatoid factors with altered $\gamma \mathrm{G}$-globulin. Immunochemistry. 8: 593.

26. Schur, P. H., and H. G. Kunkel. 1965. The reactivity of 19S anti-gamma globulins with native 7S gamma globulin. Arthritis Rheum. 8: 468.

27. Hurd, E. R., J. LoSpalluto, and M. Ziff. 1970. Formation of leukocyte inductions in normal polymorphonuclear cells incubated with synovial fluid. Arthritis Rheum. 13: 724.

28. Allen, J. C., and H. G. Kunkel. 1964. Rheumatoid factors with hidden autospecificity. Arthritis Rheum. 7: 725.

29. Oreskes, I., and B. Shore. 1966. Dilution dependent autoinhibition of agglutination in rheumatoid arthritis sera and rabbit anti-human $\gamma \mathrm{G}$ antisera. J. Immunol. 97: 600 . 
30. Hannestad, K. 1968. Rheumatoid factors reacting with autologous native $\gamma \mathrm{G}$-globulin and joint fluid $\gamma \mathrm{G}$ aggregates. Clin. Exp. Immunol. $3: 671$.

31. Pike, R. M., and M. D. Schultz. 1963. Species specificity of globulins in reactions with rheumatoid arthritis serum. J. Immunol. $91: 740$.

32. Schmid, F. R., I. M. Roitt, and M. J. Rocha. 1970. Complement fixation by a two-component antibody system: immunoglobulin $G$ and immunoglobulin $M$ antiglobulin (rheumatoid factor). Paradoxical effect related to immunoglobulin G concentration. J. Exp. Med. $132: 673$.

33. Romeyn, J. A., and D. M. Bowman. 1967. Inhibition of complementary lysis by rheumatoid sera. Nature (Lond.). 216: 180

34. Davis, J. S., IV, and A. J. Bollet. 1964. Protection of a complement-sensitive enzyme system by rheumatoid factor. J. Immunol. 92: 139.

35. Scott, R. M., and P. K. Russell. 1972. Complement fixation blocking $\mathrm{M}$ antibody. Activity of anti-dengue IgM. J. Immunol. 109: 875.

36. Kissmeyer-Nielsen, F., A. Svejgaard, K. E. Kjerbye, and T. Christensen. 1967. Blocking effect of rheumatoid factor on complement fixation by thrombocyte isoantibodies. Vox Sang. 12: 199.

37. Schumacher, H. R., and R. C. Kitridou. 1972. Synovitis of recent onset. A clinicopathologic study during the first month of disease. Arthritis Rheum. 15: 465.

38. Chamberlain, M. A., C. G. Shapland, and I. M. Roitt. 1970. Response to autologous immunoglobulin G in patients with rheumatoid arthritis. Am. Rheum. Dis. 29 : 173.

39. Wilkinson, P. C., I. C. McKay. 1971. Chemotactic activity of native and denatured serum albumin. Int. Arch. Allergy Appl. Immunol. 41: 237.

40. Kinsella, T. D., J. Baum, and M. Ziff. 1969. Immunofluorescent demonstration of an IgG- $\beta_{10}$ complex in synovial lining cells of rheumatoid synovial membrane. Clin. Exp. Immunol, 4: 265.

41. Bonomo, L., A. Tursi, D. Trizio, V. Gillardi, and F. Dammacco. 1970. Immune complexes in rheumatoid synovitis; a mixed staining immunofluorescence study. Immunology. 18 : 557.

42. Zvaifler, N. J. 1970. Further speculation of the pathogenesis of joint inflammation in rheumatoid arthritis. Arthritis Rheum. 13: 895.

43. Cats, A., and H. M. Hazevoet. 1970. Significance of positive tests for rheumatoid factor in the prognosis of rheumatoid arthritis. A follow-up study. Ann. Rheum. Dis. 29 : 254

44. Jasani, M. K., M. Katori, and G. P. Lewis. 1969. Intracellular enzymes and kinin enzymes in synovial fluid in joint diseases. Ann. Rheum. Dis. 28: 497. 